https://doi.org/10.26593/jihi.v17i1.4220.17-29

\title{
Fashion, Feminisme dan Hubungan Internasional : Perdebatan dalam Literatur
}

\author{
Ayu Chandra ${ }^{1}$, Ani W Soetjipto ${ }^{2}$ \\ ${ }^{1}$ Department of International Relations, Faculty of Social and Political Siences, Universitas Indonesia, \\ Kampus UI Depok, Indonesia, chandra.ayu92@yahoo.com \\ ${ }^{2}$ Department of International Relations, Faculty of Social and Political Siences, Universitas Indonesia, \\ Kampus UI Depok, Indonesia, ani_soetjipto@yahoo.com
}

\begin{abstract}
ABSTRAK
Artikel ini akan membahas bagaimana fashion dikaji melalui kaca mata feminis dalam studi Hubungan Internasional. Artikel ini hadir dengan melihat fashion sebagai salah satu produk dari pop culture, telah berperan signifikan dalam mendorong upaya pencapaian kepentingan suatu aktor politik - terutama sebagai alat konstruksi identitas. Kajian ini juga mendorong perkembangan kajian mengenai pop culture dalam studi Hubungan Internasional. Bahasan dibuka dengan menyajikan perdebatan literatur mengenai fashion dan feminisme. kemudian dilanjut dengan bagaimana narasi perdebatan tersebut dijabarkan dalam konteks Hubungan Internasional. Selanjutnya, melihat masalah fashion, feminisme dan Hubungan Internasional dalam konteks Indonesia dari segi produksi dan konsumsi. Artikel ini menawarkan perspektif baru dalam melihat fashion sebagai second-order representation dari politik internasional yang berdampak pada isu di ranah domestik.
\end{abstract}

Kata kunci: fashion, feminisme, Hubungan Internasional, representasi.

\section{ABSTRACT}

This article is explaining how fashion is studied through feminism and International Relations (IR) perspective. This article recognizes fashion, as one of the products of pop culture, had played a significant role in supporting politicians achieved their targets - especially as an identity construction tool. This study will also support the development of studies on the pop culture within the studies of IR. The article started with literature debates about fashion and feminism. The following part of the article tells how the debate narratives are explained in the IR context. After that, the study examines the problem between fashion, feminism, and IR in Indonesia through consumption and production point of view. This study will provide a new perspective on how fashion as a secondorder representation of international politics that influence domestic issues.

Keywords: fashion, feminism, International Relations, representation

\section{Pengantar}

Sudah memasuki tahun keempat sejak tahun 2017 lalu, presiden Joko Widodo selalu mengenakan pakaian adat dalam upacara Hari kemerdekaan Indonesia. Tahun ini presiden Jokowi memakai baju adat dari daerah Timor Tengah Selatan, Nusa Tenggara Timur (NTT) dengan perpaduan warna merah dan putih yang melambangkan bendera negara Indonesia. Penggunaan baju daerah ini dimaksudkan untuk menunjukkan identitas Indonesia yang kaya dan beragam. ${ }^{1}$

Refleksi personal yang penulis amati dari dari penggunaan pakaian adat pada hari nasional Indonesia adalah, fashion ternyata bisa bermakna sangat luas. Pakaian bisa menjadi

\footnotetext{
${ }^{1}$ Mela Arnani, Jihad Akbar, "Baju Adat Presiden Jokowi Saat Upacara Kemerdekaan dari Tahun ke Tahun," Kompas.com, 17 Agustus 2020, diakses melalui https://www.kompas.com/tren/read/2020/08/17/113204365/ baju-adat-presiden-jokowi-saat-upacara-hut-ri-dari-tahunke-tahun?page=all (pada 18 Agustus 2020 20.09).
} 
emblems of soul menurut Thomas Carlyle, ${ }^{2}$ fashion juga bisa sebagai alat komunikasi, ${ }^{3}$ atau menjadi cerminan dari identitas seseorang. Kehadiran fashion turut mewarnai perkembangan isu sosial, yang beberapa di antaranya berkaitan dengan isu feminisme, gender, lingkungan, serta ketenagakerjaan. Mengkaji fashion dari lensa gender, kita menyaksikan fashion bisa menjadi alat representasi dari citra diri yang ingin ditampilkan seseorang. Fashion mencakup hal yang bersifat konstruktif terhadap identitas individu dalam masyarakat.

Tulisan dalam artikel ini akan membahas diskursus mengenai fashion dalam kajian gender, feminisme dan Hubungan Internasional. Sebagai salah satu bagian dari budaya popular (pop culture), fashion turut berkaitan erat dengan dinamika perpolitikan global yang menyangkut konteks agen ${ }^{4}$ maupun struktur. ${ }^{5}$ Budaya popular itu sendiri menjadi tema kajian yang mulai diperhitungkan keberadaannya dalam kajian ilmu Hubungan Internasional, namun pembahasannya masih sangat minim. Selama ini topik mengenai fashion lebih banyak dibahas di luar kajian Hubungan Internasional dengan menyoroti aspek kelas, lingkungan, ketenagakerjaan, dan ekonomi.

Artikel ini akan menyajikan perdebatan literatur dalam kajian feminisme, dan menyajikan bagaimana isu fashion dibahas melalui lensa feminis. Perdebatan literatur ini akan disajikan pada bagian pertama dari tulisan. Bagian kedua, akan mendiskusikan mengenai

\footnotetext{
${ }^{2}$ Idi Subandi Ibrahim dalam "pengantar" buku Barnard, Malcolm, Fashion sebagai Komunikasi, Yogyakarta:Jalasutra (2007)

${ }^{3}$ Barnard, Malcolm, Fashion sebagai Komunikasi,

Yogyakarta:Jalasutra (2007). 66

${ }_{4}$ Merujuk pada individu sebagai aktor politik. Lihat: Anthony Giddens, The Constitution of Society: Outline of the Theory of Structuration: Elements of the Theory of Structuration, Practicing History: New Directions in Historical Writing after the Linguistic Turn, 2004.

${ }^{5}$ Merujuk pada aktor yang memproduksi sebuah aturan atau sistem dalam tatanan politik. Lihat: Giddens, 2004.
}

bagaimana fashion dikaji melalui konsep feminisme dalam Hubungan Internasional, dengan mengkaji konsep kunci tentang representasi dalam konteks Produksi dan konsumsi. Bagian ketiga menyajikan domestikasi narasi perdebatan sebelumnya dengan melihat fashion di Indonesia dalam konteks produksi, konsumsi, dan representasi.

\section{Budaya Populer (Pop Culture) dan Feminisme dalam Kajian Hubungan Internasional \\ Dalam artikel ini, penulis} menggunakan konsep budaya popular (pop culture) yang dilihat melalui kaca mata feminisme dalam Hubungan Internasional. Budaya menurut Jutta Weldes - seorang professor Hubungan Internasional dari Universitas Bristoll di Inggris, didefinisikan sebagai rangkaian praktik budaya yang mencakup proses produksi dan pertukaran makna . ${ }^{6}$ Weldes melanjutkan, praktik budaya popular esensinya menyangkut gagasan tentang power relations. ${ }^{7} \mathrm{Hal}$ ini merujuk pada peranan budaya popular yang menawarkan solusi atas praktik budaya yang pada konteks tertentu cenderung bersifat memaksa dan membatasi individu. Dalam gagasan tentang power relations, budaya bermakna politik, ${ }^{8}$ sehingga budaya popular artinya adalah praktik politik yang sifatnya popular-yang dapat diakses secara massal dan dikonsumsi oleh kalangan umum. ${ }^{9}$ Budaya popular dalam maknanya yang lain diartikan oleh Neuman dan Nexon- penulis buku Harry Porter and International Relationsmerupakan second-order representation, yaitu sebagai hal yang memproyeksikan kehidupan

\footnotetext{
${ }^{6}$ Jutta Weldes, To Seek out New Worlds: Science Fiction and World Politics, To Seek Out New Worlds: Science Fiction and World Politics, 2003, https://doi.org/10.1057/9781403982087. 6.

${ }^{7}$ Weldes.7.

${ }^{8}$ Wend dalam yakaruc

9 Adrienne Trier-Bieniek, Feminist Theory and Pop Culture, Feminist Theory and Pop Culture, 2015, https://doi.org/10.1007/978-94-6300-061-1. xiii.
} 
politik secara tidak langsung, melalui sesuatu yang bersifat fiksi. ${ }^{10}$

Nexon dan Neumann, dalam tulisannya menyatakan budaya popular dalam kajian Hubungan Internasional dapat dilihat lewat empat lensa. Pertama, budaya popular dapat disandingkan dengan kondisi politik internasional sebagai hubungan sebab akibat. Kedua, budaya popular dilihat sebagai cerminan dari motif dan proses dalam politik internasional. Ketiga, budaya popular dilihat sebagai data dengan menggunakan pendekatan hermeneutika, yakni analisis pada makna berdasarkan konten, teks, dan gambar. Keempat, budaya popular dilihat dalam maknanya yang konstitutif. ${ }^{11}$

Teori feminisme dalam studi Hubungan Internasional tumbuh dengan upaya besar untuk memperbaiki ketertinggalan perempuan dari sejarah politik internasional. ${ }^{12}$ Teori ini mengupayakan kesetaraan representasi gender dalam masyarakat dan politik internasional, khususnya melalui konstruksi narasi sejarah. ${ }^{13}$ Feminisme secara umum bergerak untuk suatu kepentingan, keadilan gender. Narasi feminisme membentuk sebuah kekayaan yang menjadikan feminisme terpecah dalam beberapa fokus aliran dan arus yang didasarkan pada perbedaan waktu dan fokus gerakan.

Dalam kaitannya dengan kajian teori feminisme, budaya popular umumnya diposisikan sebagai cerminan dan data dari realitas sosial politik terutama berkaitan dengan hal identitas. ${ }^{14}$ Budaya popular dilihat sebagai gambaran dari perubahan masyarakat, serta sumber bagi pemaknaan terhadap nilai

\footnotetext{
${ }^{10}$ Daniel H. Nexon and Iver B. Neumann, "Harry Potter and the Study of World Politics," Harry Potter and International Relations, 2006. 6.

${ }^{11}$ Nexon and Neumann. 11-20.

${ }^{12}$ Samuel Huntington et al., FIFTY KEY THINKERS IN INTERNATIONAL RELATIONS, Second Edition, Critical Theory of International Politics, 2009. 282.

${ }^{13}$ Lebih lanjut, lihat: enloe

${ }^{14}$ Trier-Bieniek, Feminist Theory and Pop Culture. xiv.
}

yang sedang dikonstruksi oleh masyarakat yang bersangkutan.

\section{Fashion dan Feminime: Perdebatan Literatur} Fashion dan feminisme mulai berjalan beriringan sejak pertengahan abad ke-19, atau ketika gerakan suffrage ${ }^{15}$ muncul di Amerika Serikat. Bersamaan dengan itu, kelompok feminis pada masa itu menyuarakan kritik mereka terhadap fashion perempuan yang bergaya Victorian yang berdampak pada kesehatan dan fleksibilitas perempuan.

Pergerakan transformasi awal pada fashion global terjadi ketika Amelia Bloomer - aktivis dan pejuang hak hak perempuan dari Amerikamengeluarkan apa yang disebut dengan bloomer costume. ${ }^{16}$ Bloomer costume adalah modifikasi celana panjang, dibawah lutut yang digunakan perempuan pada masa gerakan suffrage yang memungkinkan mereka untuk bergerak dengan fleksible.

Keterkaitan antara gerakan feminisme dan transformasi fashion melahirkan perdebatan akademis yang berlangsung dalam rentang waktu yang panjang. Perdebatan tersebut melahirkan narasi yang bergerak cair mengikuti perkembangan isu dan juga perubahan pada masyarakat yang turut didorong oleh gerakan feminisme. Penulis mengklasifikasikan perdebatan akademis mengenai fashion dan feminisme ke dalam tiga area. Pertama, perdebatan mengenai konstruksi makna fashion. Kedua, konstruksi narasi feminisme oleh industri fashion modern. Ketiga, peranan industri fashion bagi upaya pemberdayaan perempuan.

\footnotetext{
15 Gerakan yang memperjuangkan hak pilih perempuan. Lihat: https://www.britannica.com/topic/suffrage (diakses pada 4 Agustus 2020 21.08)

16 Annemarie Strassel, "Designing Women: Feminist Methodologies in American Fashion," WSQ: Women's Studies Quarterly, 2013, https://doi.org/10.1353/wsq.2013.0043. 38.
} 
Kelompok feminis awal (1850-1970) melihat fashion sebagai hal yang membatasi perempuan. Narasi ini didasarkan pada penggunaan korset, petticoat ${ }^{17}$ berlapis, dan rok yang panjang bagi fashion berempuan pada zaman Victorian yang dinilai sebagai simbol atas pembatasan potensi perempuan dalam masyarakat, dan mengekang perempuan . Selain itu, fashion juga dinilai sebagai alat pengikat perempuan pada kepatuhan dalam sistem budaya patriarki. Narasi ini mendapat dukungan dari beberapa akdemisi masa kini seperti Collins, Crane, dan Horton yang melihat fashion telah berkontribusi mendorong pembangunan atas standar kecantikan yang mengopresi perempuan, dan menjebak perempuan dalam male gaze. ${ }^{18}$ Kelompok feminis ini memaknai fashion dalam segi fungsionalnya sebagai benda pakai yang seharusnya bersifat natural dan fungsional untuk membebaskan perempuan dari pengekangan, beauty standart, dan juga male gaze.

Narasi ini mendapatkan kritik dari beberapa kelompok feminis lainya dan juga pegiat fashion. Akademisi seperti Steele, Wilson, McRobbie, Minna, dan Thornton menyatakan ketidaksetujuannya atas narasi yang dibangun oleh kelompok feminis sebelumnya. Kelompok ini merupakan akademisi fashion dan gender yang muncul pada tahun 80-an sampai akhir 90-an, yang bergerak bersama dengan kemunculan feminisme gelobang tiga yang merayakan perbedaan dan kebebasan individu. Fashion menurut kelompok ini memiliki makna yang lebih luas dari hanya sekedar fungsi utamanya sebagai benda pakai. Mereka sepakat bahwa fashion memiliki fungsi non material yang bermakna sebagai seni, keindahan, dan identitas. Narasi yang dibangun oleh kelompok ini adalah bahwa fashion memberikan makna

\footnotetext{
${ }^{17}$ Merupakan kain dalaman dalam rok perempuan. Sumber: https://www.britannica.com/topic/petticoat

${ }^{18}$ Standar perempuan yang dilihat dari sudut pandang lakilaki. Lihat: https://dictionary.cambridge.org/dictionary/english/malegaze
}

terhadap identitas individu untuk mencapai apa yang disebut dengan ideal self. ${ }^{19}$

Perdebatan selanjutnya berbicara mengenai dampak dari peranan industri fashion dalam mengkonstruksi narasi feminisme. Setelah industri fashion saat ini mengalami perkembangan yang pesat, fashion sebagai struktur dalam politik turut aktif mengkampanyekan dan mengkonstruksikan nilai-nilai feminisme, serta turut berkontribusi dalam mengkonstruksikan citra perempuan yang ideal. Beberapa akademisi menanggapi hal ini dengan berbagai sikap. Dukungan datang dari Groeneveld yang melihat fenomena tersebut merupakan salah satu peluang bagi gerakan feminisme untuk mendapatkan audiensi yang lebih luas. Menurut Groeneveld, pop culture menjadi media yang efektif untuk menyebarkan niai-nilai sosial. ${ }^{20}$ Namun dukungan tersebut mendapatkan beberapa tanggapan kritis, salah satunya dari Rottenberg. Representasi citra perempuan ideal yang digagas oleh industri fashion dan juga media dinilai mengkonsepkan perempuan yang materialistis dan mengkampanyekan gaya hidup mewah. Hal ini dinilai oleh Rottenberg sebagai penyalahgunaan terhadap konsep pemberdayaan dengan mengaitkan pada sesuatu yang bersifat materi. ${ }^{21}$ Kritik ini mendapatkan dukungan dari beberapa akademisi lain seperti Hopkins, Negrin, dan McRobbie yang menilai bahwa konstruksi industri fashion mengenai citra perempuan dan kampanye yang dilakukan atas nama gerakan feminisme dinilai hanya untuk kepentingan

\footnotetext{
${ }^{19}$ Lihat: Elizabeth Wilson, "Fashion and Eroticism," in Adorned in Dreams (London: Virago, 1985), https://doi.org/10.5040/9780755699506.ch.005. dan Valerie Steele, Fashion and Eroticism: Ideals of Feminine Beauty from the Victorian Era to the Jazz Age, Oxford University Press, 1985, https://doi.org/10.2307/1867384.

${ }^{20}$ Elizabeth Groeneveld, "Be a Feminist or Just Dress like One: BUST, Fashion and Feminism as Lifestyle," Journal of Gender Studies, 2009, https://doi.org/10.1080/09589230902812471.

21 Catherine Rottenberg, "The Rise of Neoliberal Feminism," Cultural Studies, 2013, https://doi.org/10.1080/09502386.2013.857361.
} 
komersil, dan bertujuan untuk membentuk budaya hidup yang konsumtif. ${ }^{22}$

Perdebatan ketiga, menyangkut aspek pemberdayaan tenaga kerja perempuan melalui industri fashion yang secara garis besar dapat dikategorikan dalam dua bentuk; fast fashion dan slow fashion. Perdebatan yang terjadi adalah dalam soal pemberdayaan tenaga kerja yang menyangkut aspek kesejahteraan, dilihat dari segi pendapatan dan persoalan keamanan lingkungan kerja. Menurut Myo Myo Myint, Rajah Rasiah, dan Kuppusamy Singaravello berdasarkan kajiannya pada pekerja industri fashion di Myanmar, industri fashion telah secara aktif meningkatkan pendapatan dan membuka kesempatan ekonomi bagi perempuan yang berada di sekitar kawasan industri fashion. ${ }^{23}$ Kajian ini kemudian mendapatkan kritik dari Horton dan Anguelov yang melihat bahwa peningkatan pendapatan dan kesempatan yang terjadi bagi tenaga kerja sektor idustri fashion tidak berjalan lurus terhadap peningkatan kesejahteraan tenaga kerja. Kajian ini dilakukan dengan melihat tingkat kemampuan konsumsi dan juga pendapatan tenaga kerja industri fashion di beberapa negara yang ternyata masih jauh dari standar minimum nasional di masing-masing negara. ${ }^{24}$

\footnotetext{
${ }^{22}$ Lihat: Susan Hopkins, "Girl Power-Dressing: Fashion, Feminism and Neoliberalism with Beckham, Beyoncé and Trump," Celebrity Studies, 2018, https://doi.org/10.1080/19392397.2017.1346052.Angela McRobbie, Feminism and Youth Culture, Feminism and Youth Culture, 1991, https://doi.org/10.1007/978-1-34921168-5.Llewellyn Negrin, Appearance and Identity: Fashioning the Body in Postmodernity, Appearance and Identity: Fashioning the Body in Postmodernity, 2008, https://doi.org/10.1057/9780230617186.

23 Myo Myo Myint, Rajah Rasiah, and Kuppusamy Singaravelloo, "Globalization of Industrialization and Its Impact on Clothing Workers in Myanmar," Journal of the Asia Pacific Economy, 2015, https://doi.org/10.1080/13547860.2014.974330.

${ }^{24}$ Lihat: Nikolay Anguelov, The Dirty Side of the Garment Industry: Fast Fashion and Its Negative Impact on Environment and Society, The Dirty Side of the Garment Industry: Fast Fashion and Its Negative Impact on Environment and Society, 2015, https://doi.org/10.1201/b18902. dan Kathleen Horton, “Just
}

\section{Fashion dan Feminisme dalam Kajian Hubungan Internasional: Fashion sebagai Second-Order Representation}

Pada abad ke-21 ini, perdebatan mengenai kajian fashion dan feminisme telah mengalami pergeseran isu. Bahasan mengenai fashion tidak lagi berfokus pada upaya pemaknaan terhadap fashion itu sendiri, namun lebih kepada dampak dari industri fashion dan juga representasi citra diri yang dikonstruksikan oleh fashion sebagai struktur dalam politik.

Sebagai sebuah industri, fashion telah mengalami perubahan yang besar dengan munculnya sistem produksi fast fashion. Fast fashion merupakan sistem produksi barang fashion yang mengusung sistem produksi berdasarkan pada kuantitas. Produksi yang dilakukan harus cepat dan massal. ${ }^{25}$ Sistem produksi ini telah mengubah rantai konsumsi fashion dengan mendorong percepatan dan kemudahan dalam akses terhadap barang fashion. Umumnya barang yang berlabel fast fashion memiliki harga yang murah. Harga murah inilah yang menjadi sumber masalah bagi sistem pengelolaan internal industri fast fashion. Masalah ini menyangkut pada dua ranah vital, yakni dalam hal pengolahan limbah pabrik, dan kesejahteraan tenaga kerja. Dalam sektor pengelolaan limbah, industri fast fashion bertanggung jawab atas penumpukan limbah tekstil yang sulit terurai tiap tahunnya, dan juga pencemaran terhadap aliran air oleh limbah yang dihasilkan dari proses produksi. ${ }^{26}$

Di samping dampaknya terhadap pencemaran lingkungan, industri fast fashion

\footnotetext{
Use What You Have: Ethical Fashion Discourse and the Feminisation of Responsibility" 4649 (2019), https://doi.org/10.1162/DESI.

${ }^{25}$ Anguelov, The Dirty Side of the Garment Industry: Fast Fashion and Its Negative Impact on Environment and Society. 4.

${ }^{26}$ Tatiana Schlossberg, "How Fast Fashion Is Destroying the Planet," New York Times, (3 Sept 2019), diakses melalui https://www.nytimes.com/2019/09/03/books/review/howfast-fashion-is-destroying-the-planet.html (diakses pada 30 Juli 2020 12.40)
} 
juga turut bertanggung jawab atas permasalahan ketenagakerjaan yang telah ditimbulkan. Permasalahan ini menyangkut pada pelanggaran terhadap hak atas pendapatan dan keselamatan kerja dari buruh industri fashion. Tidak hanya fast fashion saja, namun juga brand yang mengusung label high fashion-pun terbukti melakukan pelanggaran dalam masalah ketenagakerjaan. $^{27}$

Permasalahan ini mulai mendapatkan banyak perhatian setelah peristiwa keruntuhan Gedung Rana Plaza di Bangladesh pada tahun 2013, yang telah menewaskan lebih dari 1.000 pekerja yang sebagian besar adalah perempuan. Ketidaklayakan fasilitas kerja menjadi penyebab dari peristiwa tersebut. ${ }^{28}$ Pelanggaran terhadap hak atas keamanan dan kenyamanan pekerja bukan menjadi rahasia lagi bagi industri fast fashion. Para buruh bekerja di dalam ruangruang pengap yang disebut dengan sweatshop dengan tuntutan pekerjaan dan target yang tinggi. Selain itu, pelanggaran juga terjadi dalam hal pemenuhan jam kerja serta gaji yang tidak berimbang. Umumnya, untuk membuat produk yang memiliki harga jual yang murah, industri seringkali menekan biaya produksi-dengan salah satunya menekan biaya upah tenaga kerja. Seperti yang tertera dalam tulisan Anguelov, rata-rata buruh pada industri fashion di negaranegara berkembang seperti Bangladesh, Pakistan, Vietnam, Kamboja, bahkan Indonesia hanya mendapatkan upah sebesar $\$ 0.31$ per jam, dengan waktu kerja lebih dari 12 jam perharinya. $^{29}$

Posisi penting industri fashion dalam sistem perdagangan global (sebagai struktur), telah mendorong industri ini untuk turut berpartisipasi dalam pembangunan narasi

\footnotetext{
27

${ }^{28}$ Anguelov, The Dirty Side of the Garment Industry: Fast Fashion and Its Negative Impact on Environment and Society. 45.

${ }^{29}$ Ronald J. Adams, "Retail Profitability and Sweatshops: A Global Dilemma," Journal of Retailing and Consumer Services, 2002, 6989(01)00014-5. 148.
}

pemberdayaan, demi mendorong tercapainya kepentingan bisnis. Narasi yang dibangun oleh industri fashion kemudian memberikan dampak pada pembangunan image dan perubahan cara pandang masyarakat dan individu sebagai agen dalam politik internasional. Industri fashion yang sejak dulu berupaya untuk merespon perubahan masyarakat yang salah satunya didorong oleh gerakan feminisme, kini berevolusi peran sebagai struktur yang secara independen membangun narasi untuk mendorong perubahan pada masyarakat. Pembangunan narasi mengenai pembentukan citra diri, nilai-nilai kesetaraan, serta konstruksi mengenai citra perempuan yang ideal mendapatkan respon dari berbagai kalangan akademisi.

Fashion bersama dengan media menjadikan sosok selebritas dunia sebagai representasi dari citra perempuan yang ideal. Umumnya, nilai-nilai ini berkaitan dengan citra perempuan yang mandiri secara ekonomi, dan tetap menjaga perempuan serta feminitas mereka sebagai sesuatu yang bersifat lahiriah. Nilai ini menurut Rottenberg berkembang sejalan dengan perkembangan nilai post-feminism, dimana perayaan terhadap feminitas perempuan dibangun. Pembangunan image perempuan baru ini juga tidak terlepas dari bagaimana hal-hal yang sifatnya material menjadi tolak ukur dari sebuah kesuksesan menjadi sosok perempuan yang ideal. Hal ini diwujudkan dengan gaya hidup konsumtif yang berusaha untuk direpresentasikan oleh selebritas dunia. Seperti yang dikemukakan oleh Rottenberg dalam tulisannya bahwa struktur kapitalis global tengah berupaya untuk membangun image perempuan yang materialistis dengan berlandaskan pada pemaknaan yang salah terhadap nilai postfeminism sehingga melahirkan apa yang disebut neoliberal feminism. ${ }^{30}$

Pembangunan citra perempuan baru ini mendorong beberapa kritik dari akademisi lain

\footnotetext{
${ }^{30}$ Rottenberg, "The Rise of Neoliberal Feminism.” 420.
} 
yang mendukung argumen Rottenberg. Angela McRobbie sepakat atas kritik terhadap pembangunan image baru perempuan dengan argumen bahwa pembangunan wacana image baru perempuan yang terkesan cenderung sempurna-perempuan yang mandiri secara materi, ditandai dengan kepemilikan gaya hidup dan barang-barang mewah merupakan bentuk dari bagaimana struktur kapitalisme mensubjektifikasi perempuan sebagai mangsa konsumen dominannya. ${ }^{31}$ Hal ini juga seperti yang dikatakan oleh Genggler yang melihat bahwa pembangunan wacana ini sebagai bentuk komersialisasi terhadap nilai gerakan feminisme dengan turut mengkampanyekan kebebasan, kemerdekaan, dan kesetaraan yang sesungguhnya palsu. ${ }^{32}$ Kathleen Horton menyatakan bahwa praktik seperti ini memiliki tujuan besar untuk membawa perempuan dalam budaya konsumerisme dengan meng atas namakan feminisme. ${ }^{33}$

Gambaran tersebut memperlihatkan bagaimana fashion menjadi second-order representation bagi kondisi politik dari industri fashion global. Praktik kapitalisme dan neoliberalisme telah mendominasi perputaran kegiatan politik sejak kegiatan perdagangan internasional meningkat pesat akibat globalisasi. Hal ini juga menjadi gambaran mengenai pola hubungan agen dan struktur dalam politik global terkait dengan fashion, feminisme, dan politik internasional. Kepentingan dari agen dan struktur telah membawa keterkaitan antara tiga konsep tersebut.

Seiring dengan tumbuhnya kepentingan dalam masyarakat, muncul agen-agen yang bergerak dengan narasi untuk mendorong perubahan dalam masyarakat. Hal ini pula yang

\footnotetext{
${ }^{31}$ Angela Mcrobbie, "Fashion Culture: Creative Work, Female Individualization,” no. 71 (2017): 52-62.

32 Amanda M. Gengler, "Selling Feminism, Consuming Femininity," Contexts 10, no. 2 (2011), https://doi.org/10.1177/1536504211410185. 68.

${ }^{33}$ Horton, "Just Use What You Have: Ethical Fashion Discourse and the Feminisation of Responsibility." 519.
}

terjadi pada awal kemunculan gerakan feminisme. Individu sebagai agen membangun konstruksi narasi secara kolektif yang mendorong masyarakat bergerak menuju perubahan. Narasi awal gerakan feminisme adalah untuk mencapai kesamaan hak dalam politik. Narasi ini kemudian berkembang dan berubah menyesuaikan dengan kepentingan dan kondisi masyarakat. Pembangunan narasi feminisme ini mendorong perubahan dalam masyarakat, yang kemudian berpengaruh pada perubahan dari sturktur-struktur yang melingkupi masyarakat.

Fashion menjadi salah satu struktur yang mencoba untuk merespon perubahan dalam masyarakat yang menjadi sasaran konsumennya. Hal ini dapat dilihat dari bagaimana pelaku fashion seperti Coco Chanel dan Schiaparelli berupaya untuk ikut terlibat dengan nilai gerakan feminisme awal di tahun 1940-an. ${ }^{34}$ Melalui karyanya, designer fashion dunia mencoba merespon sebuah nilai dan secara aktif mendukung gerakan yang mencoba untuk menentang budaya lama (patriarki). Setelah akhir tahun 1980-an, industri fashion juga mengambil langkah untuk ikut terlibat dalam narasi gerakan perubahan masyarakat, dengan dikembangkannya sistem produksi fast fashion. Di akhir tahun 1980-an, dimana narasi gerakan feminisme gelombang tiga menyuarakaan hak atas kebebasan individu, ekspresi, identitas, dan peniadaan kelas, fast fashion hadir menawarkan solusi bagi dukungan atas narasi yang berkembang. Fashion telah menjadi alat konstruksi politis individu yang berperan dalam upaya pengembangan diri dalam mencapai value yang sesuai dengan tiap individu, serta pembangunan identitas dan representasi dari citra diri.

Melalui sistem produksi fast fashion, fashion berkembang menjadi komoditas yang

34 Caroline Evans and Minna Thornton, "Fashion, Representation , Femininity," Feminist Review, no. 38 (1991). 
besar, membangun kerajaan struktur kapitalisme yang mapan. Terjadi perubahan pada pola hubungan antara fashion dan gerakan feminisme. Struktur fashion saat ini tidak lagi hanya berperan sebagai reseptor terhadap perubahan narasi gerakan feminisme yang mendorong perubahan dalam masyarakat, namun juga turut berperan sebagai penggagas narasi yang mendorong terhadap perubahan masyarakat itu sendiri.

\section{Refleksi terhadap Fashion di Indonesia: Produksi, Konsumsi, dan Representasi.}

Berdasarkan sejarahnya, fashion perempuan di Indonesia baru mulai berkembang pesat pada pertengahan abad ke-20an, atau setelah kemerdekaan Indonesia. Perkembangan ini juga lazimnya hanya mengikuti tren-tren yang berkembang di budaya barat. Citra fashion Indonesia mendapatkan pengaruh dari beberapa hal seperti faktor sejarah, agama, dan juga tren global. 35 Seperti halnya bahasa daerah, Indonesia memiliki banyak sekali fashion icon yang menjadi kebanggaan bagi tradisi tiap-tiap daerah. Kebaya dan batik merupakan beberapa contoh kostum tradisional yang ditetapkan sebagai kostum nasional. Fashion ini membawa sejarah panjang dari perkembangan peradaban masyarakat Indonesia yang menyagkut pada nilai-nilai luhur, dan juga saksi dari peristiwa sejarah. Selain itu, fashion Indonesia juga didominasi oleh nilai-nilai keagamaan, yang dapat tercermin dari salah satu yang terbesaryakni penggunaan hijab.

Perkembangan fashion Indonesia saat ini menurut Ibrahim dapat dilihat dari tiga faktor besar. Pertama, globalisasi perdangangan. Faktor ini dapat dilihat dari banyaknya bermunculan pusat perbelanjaan yang menggiring orang pada pola hidup konsumtif. Kedua, fenomena globalisasi terhadap industri media yang memberikan referensi mengenai

\footnotetext{
${ }^{35}$ Triyanto, Kebaya sebagai Trend Busana Wanita Indonesia dari Masa ke Masa, Yogyakarta, 2010. 6-8.
}

gaya hidup mewah dengan menampilkan sosok manusia yang sempurna-pintar, kaya, dan seksi. Ketiga, gaya hidup yang natural, yang dekat dengan alam. Terinspirasi dari segi spiritualitas, dimana kekayaan digambarkan berbanding lurus dengan ketakwaan. Contohnya adalah fashion hijab syar'i, gaya hidup minimalis, dan wisata religi. ${ }^{36}$

Melihat kondisi Indonesia saat ini dalam rantai produksi fashion, Indonesia memainkan peranan besar sebagai rumah produksi bagi industri yang berkaitan dengan fashion, baik yang berskala nasional, maupun internasional. Dengan peranan tersebut, Indonesia memiliki tanggung jawab untuk memastikan kesejahteraan dalam aspek lingkungan dan juga ketenagakerjaan yang menjadi bahasan sensitif bagi industri fashion.

Mengutip pada penelitian yang telah dilakukan oleh tiga mahasiswa Indonesia pada tiga kampus yang berbeda mengenai bagaimana dampak industri garmen dan tekstil terhadap masyarakat sekitar di wilayah Sukabumi, Jepara, dan Boyolali, penulis mendapatkan beberapa gambaran. Penulis melihat bahwa keberadaan industri ini telah membawa dampak kepada masyarakat setidaknya melalui tiga aspek: ekonomi, sosial, dan lingkungan. Pada skala ekonomi, penelitian menunjukkan hasil yang mirip di tiap titik penelitian. Pertama, keberadaan industri garmen dan tekstil berperan dalam mendorong perekonomian masyarakatbaik yang terlibat secara langsung ataupun tidak dengan ketersediaan lapangan kerja dan peluang usaha bagi masyarakat sekitar. Kedua, adanya perubahan kecenderungan mata pencaharian masyarakat sekitar dari yang umumnya adalah petani menjadi pegawai industri dan pedagang. Pada skala sosial, Industri Garmen dan tekstil memberikan beberapa dampak yang mendorong terhadap keadaan sosial dalam masyarakat

\footnotetext{
36 Idy Subandi Ibrahim, Budaya Populer sebagai Komunikasi: Dinamika Popscape dan Mediascape di Indonesia Kontemporer, Yogyakarta: Jalasutra, (2003).
} 
lokal. ${ }^{37}$ Dampak dalam skala sosial ini ada yang bersifat positif dan negatif. Dampak positifnya, yakni kemajuan tingkat pendidikan dan keterampilan masyarakat sekitar. Dampak negatifnya adalah peningkatan pada perilaku menyimpang yang terjadi di masyarakat sekitar. ${ }^{38}$ Dalam skala lingkungan, industri garmen dan tekstil memberikan efek yang cenderung kurang baik, terkait dengan pengelolaan limbah pabrik yang buruk berimbas pada pencemaran terhadap tiga sumber kehidupan masyarat, yakni air, tanah, dan udara. $^{39}$

Selain dari peranan industri garmen dan tekstil, perkembangan kemajuan fashion di Indonesia juga didorong dengan keberadaan UKM (Usaha Keecil Menengah) yang turut mendorong konstruksi narasi pemaknaan fashion bagi masyarakat. Bersama dengan brand global lain yang menyandang high fashion, fast fashion, maupun slow fashion, brand lokal juga turut berperan dalam konstruksi nilai fashion, terutama dari segi konstruksi identitas.

Industri garmen dan tekstil Indonesia terhubung secara erat dalam perputaran sistem

\footnotetext{
37 Lihat: Abdul Basir, Pengaruh Keberadaan Industri Garmen Pt. Pan Brother Terhadap Kondisi Sosial Ekonomi Masyarakat Di Sekitarnya, diakses melalui http://eprints.ums.ac.id/68586/13/NASKAH\%20PUBLIKA SI.pdf Ipa Faujiah, Dampak Industri Garmen Terhadap Tingkat Kesejahteraan Masyarakat Desa Benda Kecamatan Cicurug Kabupaten Sukabumi, diakses melalui http://repository.uinjkt.ac.id/dspace/bitstream/123456789/4 4306/1/IPA\%20FAUJIAH-FITK.pdf Yesi Pratiwi, Analisis Dampak Industri Garmen Terhadap Kondisi Sosial Ekonomi Masyarakat Di Kecamatan Pecangaan Kabupaten Jepara, diakses melalui http://eprints.ums.ac.id/82278/1/NASKAH\%20PUBLIKAS I.pdf

${ }^{38}$ Abdul Basir, Pengaruh Keberadaan Industri Garmen Pt. Pan Brother Terhadap Kondisi Sosial Ekonomi Masyarakat Di Sekitarnya, diakses melalui http://eprints.ums.ac.id/68586/13/NASKAH\%20PUBLIKA SI.pdf

39 Yesi Pratiwi, Analisis Dampak Industri Garmen Terhadap Kondisi Sosial Ekonomi Masyarakat Di Kecamatan Pecangaan Kabupaten Jepara, diakses melalui http://eprints.ums.ac.id/82278/1/NASKAH\%20PUBLIKAS I.pdf
}

perdagangan fashion global, mengingat sebagian besar industri yang berdiri di Indonesia merupakan industri yang menyokong brandbrand besar dunia, terutama merek yang berlabelkan fast fashion yang di antaranya berasal dari negara Korea dan Cina. Sebagai rumah produksi bagi industri sektor fashion, negara Indonesia menghadapi beberapa tantangan, terutama berkaitan dengan kesejahteraan pekerja dan juga kelestarian lingkungan sekitar kawasan pabrik.

Tanggung jawab ini juga dipikul oleh konsumen sebagai pemegang kendali terbesar dalam pasar. Konsumen memiliki tanggung jawab yang besar dalam hal pemantauan. Konsumen yang cerdas, dapat mendorong perubahan besar dalam suatu sistem untuk bergerak ke arah yang lebih baik. Dengan percepatan pergerakan pasar dalam sektor fashion, konsumen harus jeli mengenai bagaimana produk yang mereka gunakan dihasilkan. Hal ini terkait dengan melihat isu di balik brand fashion yang kita konsumsi dari segi kesejahteraan tenaga kerja dan tanggung jawab dalam hal pengelolaan limbah.

Namun dari segi konsumsi itu sendiri tantangan yang dihadapi sangat banyak. Percepatan dan dorongan terhadap pola hidup konsumtif sangat sulit untuk dikendalikan. Hal ini bisa kita lihat dari banyaknya content creator yang menyajikan tontonan mengenai "haul" terhadap barang fashion murah dari sebuah $e$ commerce. Tantangan ini khususnya menyangkut pada konsumen usia remaja yang kesadarannya akan isu sosial dari sebuah sistem industri belum cukup memadai. Di situlah pentingnya pula peranan kampanye edukatif dari pemerintah. Namun di samping itu, saat ini telah banyak konsumen fashion yang menjadikan fashion sebagai statement atas identitas dirinya. Fashion telah dilihat sebagai alat representasi bagi citra diri, dan mempertegas identitas individu terkait gender, agama, suku, dan lainlain. 
Kemajuan pola pikir masyarakat dan perkembangan di dalamnya, telah menjadikan fashion menjadi pendukung penting bagi pemberdayaan individu dalam merepresentasikan dirinya, salah satunya berkaitan dengan identitas gender. Keberagaman dalam masyarakat dan pemahaman akan kebebasan individu saat ini telah sedikit melunturkan budaya patriarki yang cenderung mengkotakan gender dalam konteks laki-laki dan perempuan saja. Konsep gender itu sendiri telah menjadi representasi akan pemaknaan yang luas dan beragam. Setiap individu yang sadar akan identitas gender yang berbeda dengan konsep lama, cenderung memiliki dorongan untuk merepresentasikannya melalui fashion. Hal ini mendorong fashion untuk beradaptasi pada perubahan masyarakat dengan terciptanya produk-produk fashion yang sifatnya unisex. Industri fashion dengan cepat beradaptasi merespon perubahan dalam masyarakat dengan narasi yang menyuarakan mengenai kebebasan, keberagaman, dan identitas.

Selain sebagai representasi dari identitas gender, fashion di Indonesia juga memiliki fungsi representasi mengenai identitas kebangsaan dengan salah satunya kampanye selasa berkebaya yang mulai diperkenalkan oleh Komunitas Perempuan Berkebaya pada tahun 2014. Kampanye ini dibangun dengan tujuan utama untuk menjaga warisan budaya nasional dengan menjadikannya pakaian yang umum dipakai dalam keseharian perempuan. ${ }^{40}$

Kebaya itu sendiri hadir di Indonesia melalui sejarah yang panjang, yang mendapatkan pengaruh dari berbagai pihak. Kemunculan kebaya tidak dapat dipisahkan dari sejarah peradaban nusantara yang berkaitan dengan bangsa lain. Kata kebaya berasal dari Bahasa Arab 'abaya' yang berarti kain penutup

\footnotetext{
${ }^{40}$ Akhmad Muawal Hasan, "Saat Gerakan Berkebaya Dituduh Agenda Permurtadan Terselubung," Tirto.id, 13 Agustus 2019, diakses melalui https://tirto.id/saat-gerakanberkebaya-dituduh-agenda-permurtadan-terselubung-ef6G (pada 3 Agustus 2020 20.09)
}

dan diserap lebih lanjut dari Bahasa Portugis 'cabaya'. ${ }^{41}$ Sebelum mengenal konsep pakaian kebaya, perempuan Indonesia lebih familiar dengan penggunaan kemben sebagai pakaian sehari-hari. Pada abad ke-16, kebaya mulai dipergunakan pada kalangan perempuan bangsawan sebagai pakaian sehari-hari dengan memodifikasi pakaian rakyat Tionghoa yang menetap di Indonesia. ${ }^{42}$ Kepopuleran Kebaya di nusantara juga dipengaruhi oleh persebaran agama islam. ${ }^{43}$

Kebaya memiliki filosofi dan makna yang tersemat bagi pemakainya. Bukan hanya meliputi fungsi kebendaannya, kebaya dalam tradisi sejarah juga membawa fungsi dalam hal pemaknaan. Triyanto dan Sabatari dalam tulisannya melihat bahwa pemaknaan kebaya dapat dilihat dari dua sisi sifat yakni, feminim dan maskulin. Nilai feminim dari kebaya memberikan pancaran kelembutan dan keindahan dari seorang perempuan. Hal ini menyangkut pada cara pemakaian kebaya dengan berdasarkan pada pakem tradisional yang berlaku (lengkap dengan sanggul dan kain). Sedangkan nilai maskulin terpancar pada pola gerakan yang lincah dan energik, menyangkut pada penggunaan kebaya tanpa menggunakan pakem tradisional (contoh: dimodifikasi dengan celana) yang digunakan dengan menyesuaikan pada perkembangan zaman. $^{44}$

Selain identitas kebangsaan, fashion di Indonesia juga menjadi representasi bagi identitas keagamaan. Hal ini dapat dilihat dari banyaknya influencer fashion yang mengenakan

\footnotetext{
41 Triyanto, Kebaya sebagai Trend Busana Wanita Indonesia dari Masa ke Masa, Yogyakarta, 2010. 7.

42 Ninuk M. Pambudy dan Ilham Khoiri, "Aku dan Anugerah Kebaya," Kompas, April 2007 dalam Triyanto 2007. 8 .

${ }^{43}$ Triyanto, 2007. 2.

44 Triyanto dan Widyabakti Sabatari, Kebaya dalam Perspektif Gender dan Implikasinya dalam Pembelajaran, diakses melalui http://staffnew.uny.ac.id/upload/131655286/penelitian/KE BAYA+DALAM+PERSPEKTIF+GENDER+DAN+POLI TIKrevisiwuni.pdf (pada 1 Agustus 2020 22.12)
} 
hijab dan juga pada maraknya kemunculan bisnis fashion hijab di Indonesia. Di Indonesia sendiri, hijab mulai diperkenalkan pada awal abad ke-20 dengan penggunaan kain tudung oleh K.H. Ahmad Dahlan. Kebijakan mengenai penggunaan jilbab di Indonesia sempat menyentuh masa kritis di jaman Orde Baru dengan dikeluarkannya aturan pelarangan jilbab pada murid di sekolah umum. Namun kebijakan ini dicabut pada tahun 90 -an, setelah banyaknya aksi protes diselenggarakan. ${ }^{45}$ Perkembangan jilbab di masyarakat Indonesia terus berlanjut hingga tahun 2010, jilbab menjadi salah satu fashion icon yang popular di kalangan perempuan Indonesia. Hal ini turut didorong dengan munculnya berbagai majalah fashion hijab, dan desainer fashion yang memperkenalkan tren fashion hijab. ${ }^{46}$

Namun di sisi lain, ada juga konsumen fashion di Indonesia yang masih memandang fashion sebatas sebagai pakaian yang bernilai guna sebagai benda pakai. Menggunakan fashion dari sisi praktikalnya. Selain itu, banyak pula konsumen fashion (khususnya remaja) yang memainkan peranan pasif dalam berpakaian. Menjadi reseptor dari budaya luar yang sedang tren. Hal ini menunjukkan bahwa masyarakat Indonesia sebagai konsumen, memiliki pola konsumsi dan persepsi yang berbeda dalam melihat fashion. Hal ini umumnya dipengaruhi oleh perbedaan pada peranannya dalam masyarakat, lingkungan, kepercayaan, usia, dan faktor Pendidikan.

\section{Kesimpulan}

\footnotetext{
${ }^{45}$ Pingki Indrianti, The Analysis of Style and Cultural Influence on the Development of Islamic Fashion Indonesia, Case Study: Muslimah Clothing in the 19-21th Century, diakses melalui https://www.researchgate.net/publication/329012214 The Analysis_of_style_and_Cultural_influence_on_the_develo pment_of_Islamic_fashion_in_Indonesia_Case_study_Mus limah_clothing in the 19-21th_Century (pada 3 Agustus 2020 20.09)

${ }^{46}$ Ibid.
}

Dalam hal ini penulis melihat bahwa fashion berdasarkan kaca mata feminisme dalam Hubungan Internasional dapat dijabarkan dalam tiga poin sebagai berikut. Pertama, fashion yang merupakan bagian dari pop culture berperan sebagai second-order representasion dengan menjadi cerminan dan juga sumber data bagi realitas politik masyarakat disekitarnya. Fashion dari segi produksi dan konsumsi itu sendiri selalu terkait degan relasi kuasa antara agen dan struktur. Hal ini terlihat pada bagaimana narasi yang dibangun oleh suatu aktor memiliki fungsi untuk menentang narasi dari aktor lain, atau menggiring opini dan tindakan dari aktor lain. Kedua, terkait dengan representasi individu, fashion juga membawa kepentingan untuk menentang budaya mainstream dan juga budaya yang menyimpang (perilaku konsumtif dengan selasa berkebaya). Ketiga, faktor ekonomi turut memainkan peranan dalam menentukan perilaku konsumsi dan produksi seseorang, baik dengan tujuan pemberdayaan atau representasi.

\section{Daftar Pustaka}

Adams, Ronald J. "Retail Profitability and Sweatshops: A Global Dilemma." Journal of Retailing and Consumer Services, 2002. https://doi.org/10.1016/S09696989(01)00014-5.

Anguelov, Nikolay. The Dirty Side of the Garment Industry: Fast Fashion and Its Negative Impact on Environment and Society. The Dirty Side of the Garment Industry: Fast Fashion and Its Negative Impact on Environment and Society, 2015. https://doi.org/10.1201/b18902.

Basir, Abdul. Pengaruh Keberadaan Industri Garmen Pt. Pan Brother Terhadap Kondisi Sosial Ekonomi Masyarakat Di Sekitarnya. Universitas Muhammadiyah Surakarta (2018).

Evans, Caroline, and Minna Thornton. "Fashion , Representation , Femininity." Feminist Review, no. 38 (1991). 
Faujiah, Ipa. Dampak Industri Garmen Terhadap Tingkat Kesejahteraan Masyarakat Desa Benda Kecamatan Cicurug Kabupaten Sukabumi. Universitas Islam Negeri Syarif Hidayatullah (2018).

Gengler, Amanda M. "Selling Feminism, Consuming Femininity." Contexts 10, no. 2 (2011). https://doi.org/10.1177/1536504211410185

Groeneveld, Elizabeth. "Be a Feminist or Just Dress like One: BUST, Fashion and Feminism as Lifestyle." Journal of Gender Studies, 2009. https://doi.org/10.1080/0958923090281247 1.

Hopkins, Susan. "Girl Power-Dressing: Fashion, Feminism and Neoliberalism with Beckham, Beyoncé and Trump." Celebrity Studies, 2018. https://doi.org/10.1080/19392397.2017.134 6052 .

Horton, Kathleen. "Just Use What You Have: Ethical Fashion Discourse and the Feminisation of Responsibility" 4649 (2019). https://doi.org/10.1162/DESI.

Huntington, Samuel, Jürgen Habermas, Barry Buzan, Christine Sylvester, and John Rawls. FIFTY KEY THINKERS IN INTERNATIONAL RELATIONS, Second Edition. Critical Theory of International Politics, 2009.

Mcrobbie, Angela. "Fashion Culture: Creative Work , Female Individualization," no. 71 (2017): 52-62.

McRobbie, Angela. Feminism and Youth Culture. Feminism and Youth Culture, 1991. https://doi.org/10.1007/978-1-34921168-5.

Myint, Myo Myo, Rajah Rasiah, and Kuppusamy Singaravelloo. "Globalization of Industrialization and Its Impact on Clothing Workers in Myanmar." Journal of the Asia Pacific Economy, 2015. https://doi.org/10.1080/13547860.2014.974 330.

Negrin, Llewellyn. Appearance and Identity: Fashioning the Body in Postmodernity. Appearance and Identity: Fashioning the Body in Postmodernity, 2008. https://doi.org/10.1057/9780230617186.

Nexon, Daniel H., and Iver B. Neumann. "Harry Potter and the Study of World Politics." Harry Potter and International Relations, 2006.

Pratiwi, Yesi. Analisis Dampak Industri Garmen Terhadap Kondisi Sosial Ekonomi Masyarakat Di Kecamatan Pecangaan Kabupaten Jepara. Universitas Muhammadiyah Surakarta (2020).

Rottenberg, Catherine. "The Rise of Neoliberal Feminism." Cultural Studies, 2013. https://doi.org/10.1080/09502386.2013.857 361.

Steele, Valerie. Fashion and Eroticism: Ideals of Feminine Beauty from the Victorian Era to the Jazz Age. Oxford University Press, 1985. https://doi.org/10.2307/1867384.

Strassel, Annemarie. "Designing Women: Feminist Methodologies in American Fashion." WSQ: Women's Studies Quarterly, 2013. https://doi.org/10.1353/wsq.2013.0043.

Trier-Bieniek, Adrienne. Feminist Theory and Pop Culture. Feminist Theory and Pop Culture, 2015. https://doi.org/10.1007/97894-6300-061-1.

Weldes, Jutta. To Seek out New Worlds: Science Fiction and World Politics. To Seek Out New Worlds: Science Fiction and World Politics, 2003. https://doi.org/10.1057/9781403982087.

Wilson, Elizabeth. "Fashion and Eroticism." In Adorned in Dreams. London: Virago, 1985.

https://doi.org/10.5040/9780755699506.ch. 005 . 


\section{Website}

Arnani, Mela, Jihad Akbar. "Baju Adat Presiden Jokowi Saat Upacara Kemerdekaan dari Tahun ke Tahun," Kompas.com. 17 Agustus 2020, diakses melalui https://www.kompas.com/tren/read/2020/0 8/17/113204365/baju-adat-presidenjokowi-saat-upacara-hut-ri-dari-tahun-ketahun?page=all (pada 18 Agustus 2020 20.09).

Hasan, Akhmad Muawal. "Saat Gerakan Berkebaya Dituduh Agenda Permurtadan Terselubung." Tirto.id. 13 Agustus 2019. diakses melalui https://tirto.id/saatgerakan-berkebaya-dituduh-agendapermurtadan-terselubung-ef6G (pada 3 Agustus 2020 20.09).

Indrianti, Pingki. The Analysis of Style and Cultural Influence on the Development of Islamic Fashion Indonesia, Case Study:

Muslimah Clothing in the 19-21th Century. diakses melalui https://www.researchgate.net/publication/ 329012214_The_Analysis_of_style_and Cultural_influence_on_the_development_ of_Islamic_fashion_in_Indonesia_Case_st udy_Muslimah_clothing_in_the_19-

21th_Century (pada 3 Agustus 2020 20.09)

Triyanto dan Widyabakti Sabatari. Kebaya dalam Perspektif Gender dan Implikasinya dalam Pembelajaran. diakses melalui http://staffnew.uny.ac.id/upload/13165528 6/penelitian/KEBAYA+DALAM+PERSP EKTIF+GENDER+DAN+POLITIKrevisi wuni.pdf (pada 1 Agustus 2020 22.12) 